\title{
PHILelogilet
}

Servicio de Publicaciones y Difusión Cientifica

(c) (1) (9) Philologica Canariensia 25 (2019), pp. 1-18

DOI: 10.20420/PhilCan.2019.255

Recibido: 10 de enero de 2019; aceptado: 6 de marzo de 2019

Publicado: 27 de julio de 2019

\section{LA POESÍA ATLÁNTICA DE TOMÁS MORALES DESDE LO HERCÚLEO Y LA DUALIDAD APOLÍNEO-DIONISÍACA}

\author{
SANTIAGo ACOSTA Aide \\ Universidad Técnica Particular de Loja
}

\begin{abstract}
RESUMEN: La poesía modernista de Tomás Morales se ha tipificado con el uso de etiquetas caracterizadoras: poesía del mar, insular, atlántica. Estos conceptos, no obstante, definen solo tangencialmente la obra moraliana. Mediante una metodología de análisis textual de toda su producción, haciendo hincapié en los hitos más importantes de la misma, y con la aplicación del esquema mitológico nietzscheano de lo apolíneo-dionisíaco, además del ingrediente de lo hercúleo, proporcionamos una visión interpretativa más poderosa e integradora de todo su proyecto poético, resaltando las notas de su originalidad.
\end{abstract}

PALABRAS CLAVE: Tomás Morales, modernismo canario, mitología, apolíneo-dionisíaco, atlantismo

The Herculean myth and the Apollonian-Dionysian duality as tools for interpreting Tomás Morales's Atlantic poetry

\begin{abstract}
Tomás Morales's poetic work-belonging to the Spanish-American literary movement known as modernismo-has been typically characterized as an Atlantic, insular, sea poetry. Nevertheless, these are concepts which only marginally define his production. This article uses a textual analytical methodology to study Morales's major poems through the lens of Nietzsche's Apollonian-Dionysian model and the Herculean myth. Thus, I try to provide a more powerful and integrating approach to Morales's poetry with the aim of explaining its originality.

KEYWORDS: Tomás Morales, Canarian modernism, mythology, Apollonian-Dionysian duality, Atlanticism
\end{abstract}

\section{INTRODUCCIÓN}

Tomás Morales (Gran Canaria, 1884-1921) es uno de los poetas modernistas más singulares del ámbito iberoamericano por su inscripción en unas coordenadas espaciotemporales particulares. La poesía de Morales reproduce la capacidad amalgamadora del movimiento modernista, expresada con una versatilidad escurridiza frente a cualquier intento de catalogación. A pesar de ello, este autor ha sido tildado hasta el estereotipo como el poeta del mar, a cuya poesía el atlantismo y la condición insular imprimieron un carácter fuertemente espacial. Si los márgenes temporales de su obra pueden sugerir una asincronía respecto del modernismo peninsular es porque la poesía de Morales evolucionó hacia formas y temas que trascendieron el modernismo y lo hicieron transitar hacia el posmodernismo. 
Además, Morales forjó un capítulo del modernismo, el insular, en el que estableció pautas originales que lo situaron en un tiempo y espacio con referencias propias (Siles, 1985; Guerra Sánchez, 1999).

El modernismo es un movimiento trasatlántico. Los primeros indicios de la renovación modernista se produjeron de forma independiente en España y en Hispanoamérica (Aullón, 1989, 16-17), pero el fenómeno triunfó primero en América (Phillips, 1959, 50) y luego se impuso en España con la fuerza del envite ya solventado allende los mares y merced a la figura señera de Rubén Darío (Henríquez, 1962, 528), pues el nicaragüense convirtió el modernismo de ambas orillas literarias en un "común denominador" (Páez, 1999, 187). El modernismo, es acervo común, fue una corriente de renovación, una ráfaga de aire fresco en el ambiente enrarecido de la lírica en español. Para los escritores hispanoamericanos supuso su mayoría de edad, "el regreso de las carabelas" (Gomes, 2002, ix), frente al histórico tutelaje de las letras españolas desde la época colonial hasta el siglo XIX.

Con Morales, el modernismo se trasunta en un ámbito atlántico. No obstante, los membretes adjudicados al autor - atlantismo, poeta del mar, insularidad-corren el riesgo de ser confusos, ya que tienden a crear juicios previos que pueden no encontrar ajuste preciso en su obra. Si tomamos como ejemplo el atlantismo, representado genuinamente por su Oda al Atlántico, el mar, presente de forma tanto mítica como real, se asocia a otro tema de nivel superior: la victoria del poder humano sobre el medio. El océano es aquí más un espacio simbólico que real, y el protagonismo pertenece al hombre. Los poemas del mar de Morales, distribuidos en toda su obra, nos sorprenden porque, más que hablar del mar, ponen su foco visual en los puertos, en los marineros, o en evocaciones humanas que tienen como telón de fondo el motivo del mar.

\section{LOS COMIENZOS: POESÍA INTIMISTA Y EL TEMA DEL MAR}

No toda la obra de Morales es de inspiración marina. Morales es, ante todo, un cantor: de la amistad, del poder creador de la poesía, de la infancia, del amor. Su primera publicación, Poemas de la gloria, del amor y del mar (1908), es una obra iniciática en la que el autor busca su acento propio. El material poemático lo conforman ensoñaciones vagas, recuerdos infantiles, memorias familiares; pero ya empiezan a tomar forma los referentes que servirán de anclaje a su obra: el mar, la autoconciencia poética y el amor, no solo erótico, sino el amor a lo humano, a la tierra, al porvenir. Morales fue un vitalista que encontró en la sonoridad y contundencia de su poesía una forma de expresar la sed de horizontes que lo subyugaba.

En este primer libro, la crítica ha singularizado un poema representativo: "Canto subjetivo". Guerra Sánchez lo considera "trascendental para comprender el desarrollo de la poesía de Morales" $(2011,79)$. Es un poema de tanteos y equilibrios precarios. El poeta titubea entre la melancolía otoñal y un optimismo lumínico:

Yo amo el sol en el triunfo de la Naturaleza,
los ensueños heroicos de las eras triunfales
y las tardes de otoño, que tienen la tristeza
de las cosas ingenuamente sentimentales.

Luego contrapone, sin decidirse del todo, su afinidad hacia la suave impresión acústica de una naturaleza intimista y la batahola del oleaje marino, para fijarse en el poderío del mar: "Alma 
de los turbiones y del grueso oleaje". Como contraste, el poeta consigna la tenebrosa experiencia de su inmersión en la sima del yo:

¿Y después? Fueron brumas y fue un ignoto abismo de incomprensibles seres y extraña arquitectura; y ahondando en su misterio y en mi profundo mismo, divisé el aquilino perfil de la locura...

De esa negra experiencia parece haber salido con la certeza de una salvación definitiva: “[...] mas luego pasó el enervamiento / y olvidé, y olvidando volvió a tomar mi acento / la serena tersura del agua fluidora...”. Lo cierto es que, después de estos poemas iniciales, muchos de ellos con notas de profunda subjetividad, el poeta adopta una mirada extrovertida hacia el orbe, en la que pesan esos motivos que lo obsesionan: el mar, el acto creador, el progreso humano. Aquí radica una de las claves de interpretación de la poesía de Morales: su visión objetivada del mundo, acompañada de una serena contención emocional. Morales volcará su poesía hacia el encuentro del medio natural y la actividad humana, con la certeza de que esta se sobrepone a la naturaleza.

\section{El PROYECTO POÉTICO: LAS ROSAS DE HÉRCULES, MITO Y GEOGRAFÍA}

Durante su vida, Morales publicó dos obras: la mencionada Poemas de la gloria, del amor y del mar (1908) y el libro II de Las Rosas de Hércules (1919). Poco antes de morir, reunió la mayor parte de los poemas de su primer libro, añadió unos pocos poemas más, entre ellos el importantísimo "Canto inaugural", y les puso el título de Las Rosas de Hércules (libro I), que apareció póstumamente en 1922. A pesar de que esta segunda publicación fuese posterior al libro II de Las Rosas de Hércules, el hecho de que estuviera compuesta en su mayor parte por poemas procedentes del primer libro (Poemas de la gloria...) explica que Morales la diera a la imprenta como volumen I. De este modo, toda la obra de Morales quedó reunida bajo ese título genérico de Las Rosas de Hércules, lo que revela un proyecto poético unitario, del que el "Canto inaugural" era el frontispicio. La nota dominante de dicho canto es la presencia de lo mitológico.

Los motivos mitológicos son copiosos en la obra de Morales, que contiene 119 evocaciones míticas (Santana Henríquez, 2004, 385). Es indudable que el poeta canario conoció la mitología grecolatina y usó conscientemente el paradigma mitológico clásico. Sin embargo, lo singular en su apelación a lo mitológico radica, por una parte, en el libre uso que hace del mito, tanto en el contenido como en sus referencias geográficas (lo que se aprecia en el tratamiento de lo hercúleo) y, por otra, en la visión dual de los elementos míticos, en la que adquiere relevancia la dualidad apolíneo-dionisíaca. El medio geográfico tiene especial valor en nuestro poeta y las Islas Canarias son, antes que un espacio histórico, un espacio mítico. En primer lugar, por su carácter insular, pues, como afirma Martínez Hernández: "La isla es el territorio mítico por excelencia. Si hay lugares especialmente adecuados a lo imaginario son las islas" $(2010,144)$. El Atlántico es un océano mitológico en la cultura occidental y las Canarias han estado, desde tiempos inmemoriales, vinculadas a esta mitología, dentro de la imprecisión de lugar que poseen los mitos geográficos. Dice Escobar Borrego: 
el hecho de que Canarias fuera considerada en la Antigüedad como uno de los extremos del mundo [...] facilitaba la mitificación del territorio insular. No es de extrañar, por tanto, que al marco geográfico canario se adscriban mitos de abolengo grecolatino como el del Jardín de las Hespérides [...], el de Hércules y los argonautas o el de Atlas, identificado, en ocasiones, con el Teide $(2004,150)$.

Un estudio de los motivos mitológicos asociados desde antiguo a Canarias incluiría por lo menos diez temas mitológicos; en cuanto a denominaciones de origen mítico referidas a Canarias, habría cuatro fundamentales: las Islas de los Bienaventurados, las Islas Hespérides, la Atlántida y las Islas Afortunadas (Martínez Hernández, 2010, 145). Morales tiene en cuenta estos mitos (por ejemplo, el de "Islas Afortunadas" en el poema XXIV de Oda al Atlántico), pero los desarrolla libremente. Es más, propone un nuevo motivo mitológico, el de las "rosas de Hércules", que elabora mediante la extrapolación y creación de ingredientes mitológicos, dentro de un contexto en el que prima la ambivalencia y una deliberada ambigüedad. El motivo de las "rosas de Hércules" se relaciona con el Jardín de las Hespérides, una de cuyas localizaciones mitológicas son las Islas Canarias, atestiguada ya en el siglo I d. C. en la obra del geógrafo latino Pomponio Mela (Martínez Hernández, 2010, 148). El término de "rosas" remite metonímicamente al de "jardín", y Hércules estaba indirectamente vinculado a los mitos grecolatinos sobre las Canarias mediante el mito de las "Columnas de Hércules" y el ciclo de los trabajos. El resultado es que Morales reelabora el mito hercúleo para adaptarlo al ámbito atlántico (González Morales, 2015, 106), proporciona una referencia geográfica novedosa a determinados elementos mitológicos clásicos y desarrolla una línea conceptual más general que se inscribe dentro de la dualidad nietzscheana de lo "apolíneo-dionisíaco".

\section{LO HERCÚlEO Y LA DUALIDAD DE LO APOLÍNEO-DIONISÍACO: EL “CANTO INAUGURAL"}

Morales comparte con los modernistas el uso del mito como forma de recreación de un mundo idealizado definido por la belleza (Escobar Borrego, 2005), y a esta finalidad decorativa añade otra funcional en su poesía: la de servir de matriz fundacional de un espacio poético (Guerra Sánchez, 1999; González Morales, 2015). En la adaptación de la mitología clásica a un nuevo espacio geográfico con su derivada histórico-social y económica, el poeta insular amplía los significados de los motivos míticos y los fusiona a su albedrío. En este sentido, lo apolíneo-dionisíaco se nos sugiere como un medio interpretativo especialmente clarificador para advertir la originalidad moraliana en la aplicación de lo mitológico. La matriz mitológica "apolíneo-dionisíaco", no siendo originalmente grecolatina, pues parte de la interpretación de Nietzsche (El nacimiento de la tragedia, 1872), remite sin embargo a dos de los mitos más conocidos de la Antigüedad clásica: Apolo, dios de la belleza, y Dioniso, dios del vino. Lo apolíneo-dionisíaco se ha usado con frecuencia para analizar diversas obras literarias. La dualidad nietzscheana (unida a la figura de Hércules, a quien Morales pone como contrapunto humano de las simbólicas "Rosas") aporta una comprensión de relevancia especial para la obra que juzgamos. Ello se demuestra en el hecho de que lo apolíneo y lo dionisíaco se perfilan con claridad en el "Canto inaugural”, poema que preside el gran proyecto poético de las "Rosas de Hércules".

El "Canto inaugural" es una pieza que proclama, desde su fuerza sensorial, empuje rítmico y retórica mitológica libremente recreada, la adscripción modernista del poeta. Morales la escribió para colocarla como portada y piedra angular de su obra. El poeta reinterpreta el mito 
de Hércules para vincularlo con la geografía insular canaria, todo lo cual puede encuadrarse en el marco interpretativo nietzscheano.

La primera imagen del poema es la del semidiós enseñoreado de las tierras occidentales. Su figura se proyecta con una enorme fuerza y vitalidad dionisíacas, a las que cede paso la naturaleza:

Bajo las rubias ondas del estío inclemente, por apacibles cuencas y huyentes peñascales, Hércules recorría las tierras de Occidente.

$[\ldots]$

Iba alegre, poseso de un desmedido empeño; el loco aturdimiento tronchaba los arbustos, vagando a la ventura, bárbaro y zahareño.

Es el héroe vencedor de todas las pruebas a que se ha sometido, según el ciclo mítico de los trabajos de Hércules. En estos versos iniciales y en los posteriores, Morales se mantiene fiel al guión mitológico de lo hercúleo, dentro de una amplia libertad, porque no persigue una paráfrasis del mito. Reproduce el conflicto entre el héroe semidivino y el sol, Helios, cuando aquel lleva a cabo el décimo de sus trabajos (hacerse con el ganado de Gerión). En el "Canto", Hércules, irritado por el calor, lo encara desafiante y le lanza un potente flechazo:

Tiende la cuerda el ágil mancebo; de repente, del curvado artificio por la sutil garganta, parte la aguda flecha vertiginosamente.

iFue tan fiero el impulso, fue la violencia tanta, que al recobrar el arco la primitiva hechura, sintió el arquero, un ápice, ceder la firme planta!

No se olvide que Helios está asociado a Apolo, dios de la belleza y de lo lumínico. El ataque al sol retrata a Hércules como un héroe antiapolíneo, es decir, dionisíaco, dentro de la antinomia nietzscheana. Tras este momento de clímax protagonizado por la ira de Hércules contra el sol, la narración poética da un brusco giro anticlimático. El astro se retrae y se oculta entre nubes: "Enojado el profuso monarca de la altura, / [...] cubrió la faz pletórica con densa nube oscura". No debe sorprender esta reacción del dios solar: Apolo, en la argumentación nietzscheana de lo apolíneo, es el dios de la moderación, de ahí que su respuesta sea mesurada. Inmediatamente, se produce en el poema otro comportamiento que amplía la transición anticlimática: Hércules se distiende después del alarde de temeridad y descubre un vergel de rosas, al que acude atraído. Embriagado por los efluvios de las rosas, el héroe cae en un profundo sueño:

Vuelve la vista en torno; cabe los matorrales, trazando una ancha faja de penumbra olorosa, corría un largo seto de silvestres rosales.

$[\ldots]$

Ahora, pesaroso de las glorias pasadas, refrenando el orgasmo de los instintos duros, intenta tocar, tímido, las urnas perfumadas:

$[\ldots]$ 


\begin{abstract}
Apriétanle el cerebro los vahos encendidos y borracho de aromas, deja doblar, incierto, sobre la oliente alfombra, los músculos vencidos...
\end{abstract}

Serenidad... Triunfaba del horizonte abierto, de nuevo el Sol magnífico; [...]

Hércules ha sido vencido por el sol ("Triunfaba [...] el Sol magnífico") mediante la belleza aromática de las rosas. La derrota ha sido gradual: primero la curiosidad, luego la vacilación ("intenta tocar, tímido"), finalmente la postración ("deja doblar, incierto [...] los músculos vencidos"). Lo irónico es que la venganza del sol, que consiste en enervar al héroe, se produce mediante el recurso al sueño: recuérdese que el sueño está ligado a lo apolíneo. Este momento, antitético respecto de la primera parte del poema, protagonizada por la acción impetuosa del personaje, tiene una intención simbólica. Mediante la imagen del lecho de rosas, la cercanía del mar (“iFrente al joven dormido, el claro mar sonaba!") y la ubicación occidental del lugar poético (Hércules ha ido desplazándose hasta el confín de las tierras de Occidente), el poema sugiere que el héroe semidivino ha llegado al mítico Jardín de las Hespérides, trasmutado en un nuevo motivo, el de las "rosas de Hércules":

Tal, olvidando un punto las gestas azarosas -crepuscular paréntesis en las heroicas lides-, bajo un cielo del Lacio y en un lecho de rosas, soñó su primer sueño de amor el gran Alcides.

Con este serventesio concluye el "Canto inaugural", cuya intención es situar, desde un punto de vista geográfico y poético, el ámbito desde el que el poeta desea desarrollar su proyecto literario. Hay dos símbolos explícitos en el poema:

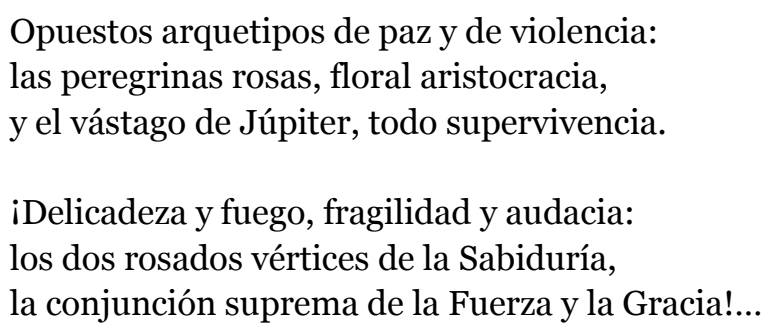

Los dos símbolos, la fuerza de Hércules y la belleza de las rosas, no son elementos accesorios: se trata de los dos polos de la dualidad apolíneo-dionisíaca. Recuérdese que para Nietzsche el sueño y la embriaguez (presentes en el "Canto inaugural") son los estados fisiológicos que se corresponden, respectivamente, con lo apolíneo y lo dionisíaco.

Las rosas son en el "Canto" la verdadera novedad desde el punto de vista mítico y simbólico, pero no existe unanimidad en su significado, según las diversas interpretaciones. Santana Henríquez (2003) constata que las rosas no son parte del mito hercúleo y que, dentro de un sistema de contrarios, expresan, frente al instinto violento del héroe, la paz y la aristocracia. Escobar Borrego $(2004,155)$ ve en las rosas la trasposición del mito de Onfalia, de cuya dulzura y gracia se enamora el héroe. González Morales (2015) atribuye a las rosas el valor de simbolizar la poesía y el amor, ante los que el semidiós se rinde; además, en la oposición 
mencionada ve la antítesis de lo femenino (las rosas) y lo masculino (Hércules). Como se advierte, las rosas son un factor aglutinador de gran poder expresivo que agrupa los significados mencionados; primeramente, son un motivo apolíneo porque plasman la belleza y la plasticidad en las que se adormece la desmesura dionisíaca de Hércules, encarnación del instinto violento; en segundo lugar, las rosas simbolizan lo dionisíaco, al embriagar al héroe con su poder narcotizante y voluptuosidad dionisíaca. De este modo, Morales, en aparente tono menor, configura un símbolo mitológico - las rosas- que, subyugando al héroe mítico por antonomasia, se convierten en sustrato mitológico de las Islas Canarias y amalgaman los valores dionisíaco y apolíneo de los mitos clásicos.

\section{VITALISMO Y HUMANISMO MORALIANOS}

El vitalismo de Morales guarda también consonancia con la obra nietzscheana, pero sin su ingrediente trágico. La fuerza del héroe con su carácter dionisíaco se traduce en el talante humanista de esta poesía, en la que Morales introduce una visión optimista referida a la capacidad del ser humano para, mediante el ingenio y el uso del artificio, vencer los poderes elementales de la naturaleza, protagonizados por el mar. Y todo ello bajo la convocatoria fundacional del mito. Lo dionisíaco suele primar como nota ligada a lo humano: Morales cantará muy frecuentemente la audacia humana en la lucha existencial y le seducirá la capacidad que tiene el hombre de sobreponerse a las condiciones del medio. Lo dionisíaco aflorará asimismo en el amor como fuerza arrebatadora, a la que Morales acude a lo largo de toda su poesía. Lo apolíneo surge dialécticamente como contención y contraparte de lo dionisíaco, sin que estos dos momentos se anulen mutuamente.

Si nos adentramos en otros pasajes de la poesía moraliana, pero todavía en la primera obra publicada, Poemas de la gloria, del amor y del mar (1908), vemos que la última sección dedicada al mar puede tomarse como hilo conductor de la propuesta significativa de Morales y como transición hacia otras etapas de su poesía. La sección "Poemas del mar" fue la que tuvo mayor repercusión pública:

La perspectiva que mostraba Morales en torno al tema marino era prácticamente inédita en la poesía hispánica del momento, sobre todo por haber logrado un inusitado equilibrio entre elementos en apariencia opuestos, particularmente entre la ensoñación poética, de carácter puramente simbolista, y un espacio geográfico en principio realista, como es el de la vida portuaria y todo lo que ello implica (Guerra Sánchez, 2011, 22).

Desde el comienzo del segundo poema de la sección "Poemas del mar", se hacen patentes las notas dionisíacas de potencia asociadas al mar, pero unidas también a lo humano. El mar de Morales nunca se presenta como motivo inmanente, sino como telón de fondo de la actividad humana. En "Poemas del mar", el mar posee un "bárbaro fragor", las olas se manifiestan con "rudos alborotos" y golpean la cubierta de los barcos "con recia algarabía", la borrasca es "fiera". En el nivel humano (el poeta, los marinos) y el de sus artificios (las naves), el poeta se siente unido al mar "con un salvaje amor", los gavieros son "atrevidos", los marinos son "gentes de recios músculos, corazones gigantes", y los barcos arriban a puerto "cual monstruos jadeantes". No se trata, entonces, de un elogio al mar, sino de la conquista de los océanos por la audacia de los marinos lo que remite al paradigma de lo hercúleo. Este aspecto es decisivo: los hombres de mar y las figuras humanas que entran en relación con el mar se revisten de caracteres claramente hercúleos, no necesariamente en la apariencia física, sino en 
especial en lo relativo a los rasgos de carácter: la intrepidez, la temeridad, la reciedumbre... Los atributos aquí apuntados se reiteran en los poemas de toda la sección.

Hay otro motivo relacionado con el mar que resulta clave: la preponderancia del puerto, con valor de símbolo. De los diecinueve poemas que conforman la serie, dieciséis mencionan el puerto, el muelle, o tienen como ambiente tácito lo portuario. El puerto es un artificio humano; puerto y naves son en esta poesía manifestaciones de la fuerza y la inteligencia del hombre. Y en el puerto se mueven esos argonautas modernos que son los marinos de profesión, para quienes reiteradamente entona el poeta su admirada salmodia.

\section{LA CIUDAD Y EL PUERTO EN "POEMAS DE LA CIUDAD COMERCIAL”}

El siguiente conjunto poemático en el que confluyen los asuntos de índole portuaria y marina, imbricados con las notas de cosmopolitismo, exotismo y mitología, es el titulado "Poemas de la ciudad comercial" (libro II de Las Rosas de Hércules). Gracias a esta serie de poemas, Morales entra en el grupo de poetas modernistas destacados que abordaron el tema urbano (Herrería, 2014, 180). Aquí el nuevo escenario es la ciudad y, en concreto, la ciudad de Las Palmas de Gran Canaria. La centralidad de la ciudad en esta sección poemática está doblemente justificada. En primer lugar, la modernidad surge en íntima relación con el desarrollo urbano (Guerra Sánchez, 1999, 61). La ciudad que está asociada al modernismo, como afirma Cortés-Rocca, no es solamente el espacio que contrasta con lo rural, sino el "espacio sin fronteras, como punto de conexión con el mundo" $(2009,146)$. Aquí es patente el significado de la ciudad como apertura al mundo, que se traduce en cosmopolitismo y exotismo.

En "Poemas de la ciudad comercial" (en adelante, "Poemas"), Morales instaura un esquema que repetirá posteriormente en la Oda al Atlántico: referencia el origen mitológico del lugar geográfico, para pasar luego al presente histórico. En el origen coloca las fuerzas sobrenaturales, de orden mítico; en el presente, las fuerzas humanas, de naturaleza técnica y económica. Persistirán en "Poemas" los rasgos de cosmopolitismo y exotismo, así como el de maquinismo, íntimamente relacionados por el motivo dominante del comercio: es la acción comercial la que convoca medios de transporte, la que atrae a comerciantes de distintos lugares del mundo y procura productos exóticos. Todo ello, desde luego, dentro del marco de lo apolíneo como exceso y desmesura.

Guerra Sánchez $(1999,73)$ afirma que Morales realiza en "Poemas" el paso del mito de los orígenes al mito del progreso. Este aserto requiere una matización: el progreso ya no es aquí un mito, sino una realidad que no ha sobrevenido por intervención de fuerzas sobrehumanas, sino por la gestión de capacidades humanas. Se da un proceso de simbolización de la riqueza, el dinero y el capital, productos todos ellos del trabajo comercial. El uso del mito fundacional está, no en relación directa con el comercio (aunque hay una cierta relación por la mención del dios Mercurio, divinidad del comercio), sino con la ciudad. Morales traslada a la ciudad la índole mítica de la isla y del propio océano (nótese en el conjunto poemático la referencia al "mito de Atlante" y de Alcides, nombre alternativo de Hércules). El poeta hace surgir la ciudad casi de las aguas, asentada en un arrecife:

En pleno Oceano, sobre el arrecife de coral cambiante que el mito de Atlante 
nutriera de símbolos y de antigüedad, donde el sol erige su solio pagano

y Céfiro cuenta, perenne, la hazaña de Alcides, se asienta la ciudad que hoy canto: imi clara ciudad!

Morales convoca, para la fundación de su ciudad, diversas figuras mitológicas: Helios, Apis, Deméter y, en especial, Mercurio, que vaticina el futuro esplendor comercial del lugar. Sin solución de continuidad, tras la evocación de las divinidades tutelares de la ciudad, el poeta pasa al momento presente y describe la actividad económica de la urbe. La fraseología se vuelve deliberadamente prosaica, el ritmo se acelera y abundan las enumeraciones y los verbos que indican movimiento:

iEs la Plaza, el triunfo, la contienda diaria!

Es la puesta en marcha de esta maquinaria

de ruedas audaces y ejes avizores,

que el cálculo impulsa y el oro gobierna.

iCólquida moderna

de los agiotistas y especuladores!

("Canto a la ciudad comercial")

La modernidad va unida a la urbe y la plasmación de ese desarrollo se reproduce como fruto de la audacia humana (trasladada mediante un procedimiento metonímico a las ruedas: "ruedas audaces") y de la lucha ("la contienda diaria"), que trae como consecuencia el "triunfo". De nuevo concurre la visión dionisíaca que hemos identificado en la poesía moraliana con ocasión del Hércules del "Canto inaugural". Aquí ("Canto a la ciudad comercial”), lo dionisíaco es la fuerza humana que triunfa sobre la base del ingenio y el trabajo:

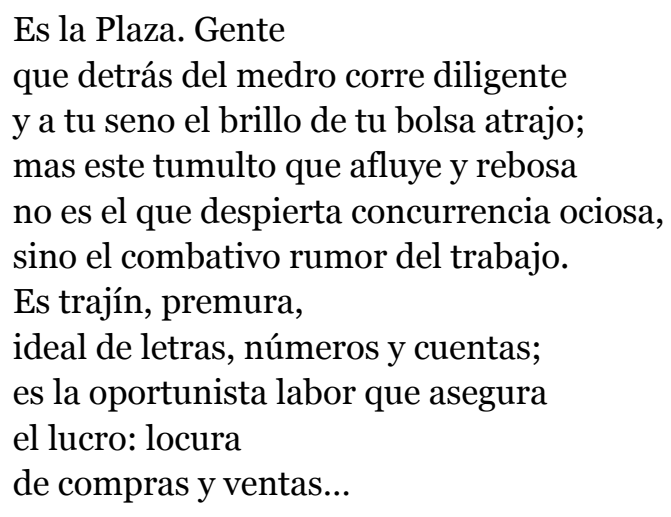

Como Hércules engullía los espacios movido de una energía explosiva en el poema "Canto inaugural", ahora la gente de la ciudad bulle en los distintos ámbitos urbanos presa de la locura del lucro. La diferencia está en que en este caso el héroe no es una figura mitológica, sino un personaje colectivo (son reincidentes los sustantivos que se refieren a la colectividad: "gente", "tumulto", "concurrencia", "muchedumbre"), y la riqueza aflora con abundancia. Todo se da en una típica desmesura dionisíaca. La isla da sus frutos agrarios, la ciudad los contabiliza y negocia, y el puerto los despacha, en una cadena de actividad inagotable. La ciudad, en efecto, se vuelve hercúlea. El dominio del medio marino por parte de los hombres no es irrelevante en 
esta carrera expansiva de la ciudad, ya que es justamente su estratégico puerto, en el que crepita la actividad de la maquinaria, el que hace posible su avance:

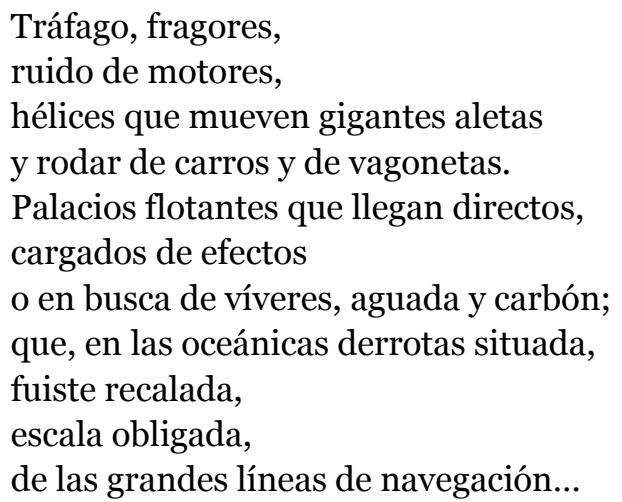

("Canto a la ciudad comercial")

Otros poemas de la serie, más breves, de menor aliento mitológico, confirman la visión dionisíaca. "La calle de Triana" (calle comercial de la ciudad) aparece como la arteria por la que discurre la agitación mercantil. La vitalidad dionisíaca queda retratada sin paliativos:

Todo aquí es presuroso, todo es vida;

y ebria de potestad, en la refriega,

la ciudad, cual bacante enardecida,

al desenfreno comercial se entrega...

El poema "Estampa de la ciudad primitiva" continúa en la misma línea, esta vez explotando el contraste entre el silencio del amanecer y los primeros ruidos del despertar de las fábricas, anunciadores del inminente frenesí acústico de la ciudad comercial que representan la música dionisíaca de la actividad capitalista:

Los primeros rumores de la jornal faena

difunden en la bruma su vuelo mercantil,

y el agudo silbato de una fábrica llena

la ciudad con el júbilo de su clamor fabril.

El poeta introduce otros contrastes en la sección. Frente al desenfreno ruidoso que domina la calle de Triana, las tiendas de turcos (situadas en la misma calle) ponen una nota de antagonismo con su parsimonia oriental. El poema abunda en enumeraciones de los artículos que los bazares de turcos exponen a la venta, y que son ocasión para una fuga ensoñadora a los lejanos lugares de donde provienen (“cofrecillos de sándalo”, “jarrones repujados”, "damasquinados", "porcelanas", "sedas", "tapices recamados”, "bisutería”). La diferencia respecto de las enumeraciones de la primera parte de la sección de "Poemas" radica en que el ritmo se refrena, se diluyen los significados verbales que denotan actividad, y la mirada poética se singulariza en los detalles. Entramos, además, en una atmósfera distinta, de ensoñación y fantasía. El exotismo apunta hacia un contraste entre lo oriental y lo occidental; si el activismo hercúleo es occidental en su origen y despliegue, lo oriental (en este contexto) connota quietud. El efecto que se crea es de abigarramiento visual y de cierta irrealidad: 


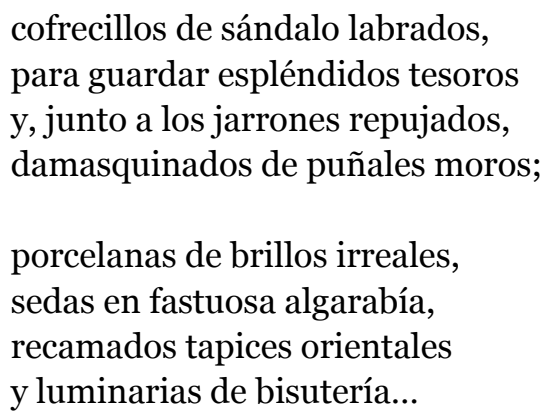

Lo que llama la atención en los poemas que cantan la febril actividad comercial es la postura aséptica del yo lírico, que no enuncia ningún comentario desfavorable o crítico frente a la exacerbación del trabajo capitalista y comercial, en el que parece agotarse la vida ciudadana. Ni siquiera un dejo de ironía se expresa en el entusiasmo con que el poeta canta las glorias del dinero y las transacciones. Como Hércules se embriagó del aroma de los rosales en el "Canto inaugural", los actuales habitantes de la ciudad insular se entregan al frenesí del lucro ante la mirada objetiva del poeta, que no emite ningún juicio moral. En este sentido, estimamos que la falta de sentido crítico y el objetivismo en la mirada poética son una cualidad nietzscheana en esta poesía. En El nacimiento de la tragedia Nietzsche defiende una concepción amoral del arte, en el sentido de soberanía de esta actividad frente a los juicios propios de lo moral, hasta el punto de que propone "un dios-artista completamente amoral y desprovisto de escrúpulos" (2009, 32).

Hay excepciones, en otros poemas del conjunto, a este "objetivismo amoral". En "La calle de Triana”, tras describirse la convulsión económica de la ciudad, surge un rasgo apolíneo de mesura junto con una tenue valoración moral: "Y al alma, que es, al fin, mansa y discreta / tanta celeridad le da quebranto...”. Otra serie de contrastes frente a la acción desenfrenada de los negocios y las compraventas se produce en dos poemas más. En "Calle de la Marina”, el poeta se adentra en una zona sórdida de prostitución e inseguridad. El "yo" lírico modera su entusiasmo por el desarrollo urbano y comercial para constatar que este es el otro lado de aquella realidad de pujanza. Cita el arrabal de suciedad y mala vida como la cara oculta de los puertos de mar:

Calle de horror. Impune encubridora para todo lo infame o subrepticio, por donde la miseria es corredora y se amanceba el crimen con el vicio.

Tascas, burdeles, casas que previenen con su aspecto soez. Toda la incuria de los puertos de mar, en lo que tienen de pendencia, de robo y de lujuria...

Si en los poemas que describían el auge económico de la ciudad se mostraba la visión objetivista del poeta, en este otro poema esa mirada está cargada de valoración negativa por el léxico utilizado, en especial los adjetivos de reprobación ("copla obscena”, "torvas figuras", "innobles cataduras", "sucios paredones”, "callejón siniestro”). La carga de desaprobación moral es evidente y el poeta ha abandonado su actitud imparcial. Algunos críticos hablan de 
ironía en este juego de contrastes; González Morales va más allá y estima que el poeta articula un discurso poético crítico contra la ciudad y "se rebela contra las imposiciones de la modernidad, el imperialismo, el capitalismo y la despersonalización que estos conllevan" $(2015,501)$. En otro poema, titulado "El barrio de Vegueta", el hablante lírico, abandonando también su visión objetivista, se inclina en su preferencia por este sector recoleto e histórico de la ciudad. Más que un rechazo de la modernidad, nos parece preferible ver, en esta confrontación de visiones del yo lírico, la contraposición de lo dionisíaco y lo apolíneo. Haríamos mal en sacar consecuencias de orden moral en el sentido de colegir que el sujeto lírico descalifica la modernidad o el progreso comercial. Lo que hace, sin dejar de plasmar su nostalgia por la ciudad antigua que va muriendo, es poner en pugna las dos fuerzas que operan en la urbe y que le dan su configuración propia: lo dionisíaco en el desenfreno comercial (del que la sordidez de la Calle de la Marina no es sino un aspecto) frente a lo apolíneo del Barrio de Vegueta, donde predomina la quietud, la mesura de la tradición.

\section{LA CÚSPIDE DEL MODERNISMO ATLÁNTICO: ODA AL ATLÁNTICO}

La Oda al Atlántico significa la culminación de la obra moraliana. Apareció en el libro segundo de Las Rosas de Hércules (1919) y, por tanto, representa la última etapa creadora del poeta. Aunque la Oda está situada en el libro antes que los "Poemas de la ciudad comercial", Sebastián de la Nuez, que ha estudiado el proceso de escritura de la Oda, afirma que esta es posterior a los poemas comerciales $(1973,106)$. La Oda es una obra de gran aliento, si no en su extensión, pues consta de 350 versos repartidos en veinticuatro poemas, sí en su unidad y proyección temáticas, en el brío airosamente sostenido de los alejandrinos (mayoritarios en la Oda), el tono retórico y exaltado, la cuidada selección léxica, el alcance universal y el efecto sinfónico. Estamos, sin duda, ante una de las piezas más representativas de Morales, la más hermosa. De la Nuez (1973, 90-91) ha realizado una útil división de la Oda sobre bases conceptuales: una primera parte de introducción y presentación de los orígenes míticos del océano (primeros ocho poemas), una segunda parte centrada en el Hombre y el Mar (siete poemas siguientes), la tercera parte de alabanza a los hombres del mar (ocho poemas posteriores) y una invocación final al mar Atlántico.

Desde el punto de vista mitológico, tanto Escobar Borrego $(2004,167)$ como De la Nuez (1973, 94-95) opinan que el tema de la Oda se configura en torno al mito adámico judeo-cristiano:

En la Oda al Atlántico se convierte el mito en una alegorización del Hombre primitivo del que surge [...] [una] fuerza genésica también, que le lleva a la conquista del gran Mar [...] por medio de la creación de la Nave, creación también de su mente, símbolo femenino, "mitad sirena, mitad ave" con un torso desnudo de mujer en la proa, para vencer al Mar-Padre, al propio ZeusDios (De la Nuez, 1973, 107).

Como se ve en la cita anterior, para De la Nuez existe una amalgama de mitos judeo-cristianos y grecolatinos, con ingredientes simbólicos freudianos. González Morales, por su parte, advierte la unión de la cultura clásica y el espacio atlántico, además de postular el peso mitológico que tienen en esta composición "la Teogonía de Hesíodo, la Odisea de Homero y las Argonáuticas de Apolonio de Rodas" (2015, 313 ss.). Ciertamente, hay una fusión de geografía y mito, pero es pertinente apreciar que persiste la validez del choque entre los polos 
dionisíaco y apolíneo, así como la acción de lo hercúleo como paradigma. De este modo, el planteamiento se simplifica y adquiere mayor fluidez. ¿Qué papel desempeña el Mar en este sistema interpretativo? Siguiendo la visión nietzscheana, en la Oda nos encontramos con un Mar que representa la vida y la muerte, como el Uno primordial de Nietzsche, del que, mediante el principio de individuación, surge la vida y al cual el regreso supone la muerte, generadora a su vez de nueva vida. En la Oda, el Mar aparece como principio de vida y de muerte, infinito, primordial. Los mitos judeo-cristianos no tienen funcionalidad, ya que en estos el principio es siempre el Dios trascendente cuyo poder creador se manifiesta en la Palabra. La creación judeo-cristiana nunca se confunde con la divinidad, por repugnancia del panteísmo, mientras que, en la Oda al Atlántico, Morales se mueve en un ámbito de sacralización del mundo, pagano en su visión mitológica. Ello no excluye que el símbolo marino se cargue de diversos significados. En el poema introductorio y conclusivo, el Mar es el "gran amigo", el mar de la infancia, el Atlántico geográficamente marcado, el mar cercano al ánimo del poeta. A lo largo de la Oda, sin embargo, ese mar se transfigura con una potencia simbólica y mitológica singulares.

Las primeras composiciones de la Oda (II-VIII) presentan, con luminosidad y quietud apolíneas, un mar original, primordial, como primer espacio existente. Morales no habla de la creación del mar (no poetiza, entonces, en términos judeo-cristianos); postula un mar eterno, inmóvil, si bien es un mar muerto, desprovisto de vida y movimiento (González Morales, 2015). La representación de este piélago es casi geométrica, como una inmensa plancha en perfecto equilibrio de fuerzas físicas:

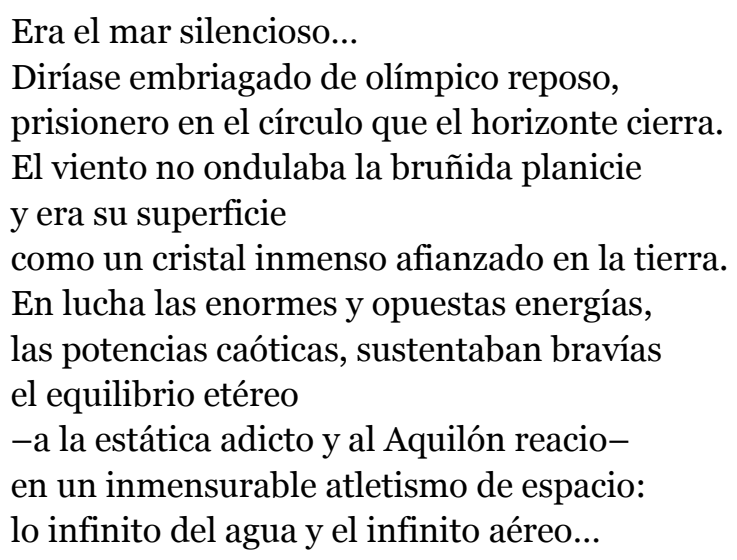

$($ Oda, II)

En la tercera composición este equilibrio se disloca ("Mas de pronto una noche claudican los puntales") y aparece Poseidón bajando del cielo en un carro para tomar posesión de su reino acuático. El cuarto segmento es un cuadro vivísimo de la aparición del dios marino, de gran belleza plástica. La irrupción del dios agita las aguas, las olas se enseñorean de la antigua superficie inmóvil y adviene la vida (poemas V y VI):

Quedó el hechizo roto: las aguas se curvaron flexiblemente y, raudas, en amoroso allego, por toda llanura gloriosa se buscaron, con langor de caricia y agilidad de juego. Llenó un rumor vehemente los ámbitos difusos; 
los gérmenes profusos

a actividad trajeron sus faces vibratorias

y describieron, plenos de estímulos vitales,

maravillosos peces, sinuosas trayectorias,

moviendo apresurados sus aletas caudales.

$($ Oda $\mathrm{VI})$

Este ámbito vital que se despliega en las aguas oceánicas es todavía de aliento apolíneo, lo que corrobora el segmento VII, con la aparición de la luz auroral y la mención del dios Apolo. Nada hay todavía dramático ("Todo era formidable e infantil: sonriente / Apolo se ofrecía coronado de rosas"). El poema VIII es prolongación de esta radiante imagen de un mar original. El sol (Apolo) emite su luz esplendente y en este marco surge ya un indicio del drama venidero, que nos remite al "Canto inaugural", cuando el dionisíaco Hércules, arrebatado de soberbia ira, disparó sus flechas al sol estival. En la Oda, de forma análoga, el mar elude la radiación solar:

$$
\begin{aligned}
& \text { El sol, en llamaradas rotundas, destilaba } \\
& \text { su radiación actínica; } \\
& \text { al monstruo la excitante caricia espoleaba } \\
& \text { y el lomo azul fugaba } \\
& \text { esquivando la acerba persecución lumínica... }
\end{aligned}
$$

(Oda VIII)

El segmento IX supone una ruptura: la aparición del hombre. Este hombre primigenio se supone ya existente (no es el primer hombre adámico). La imagen de este humano, en cuyo ánimo comienzan a bullir las pasiones dionisíacas ("fascinado por el prodigio inmenso"), y que contempla el mar desde un acantilado, está eficazmente dibujada por Morales, con gran efecto visual:

Y el hombre, fascinado por el prodigio inmenso, desde los roquedales del litoral, suspenso, contemplaba el milagro. Su presencia añadía un elemento nuevo a la gracia del día. Inmóvil, en las redes del estupor prendido, sobre la costa brava, no era más que un resalte de la roca, perdido en la extensa vorágine que ante sus pies rodaba.

Este hombre es de nuevo el héroe hercúleo ("Mas era osado y fuerte"), el bárbaro redivivo del "Canto inaugural" con su instinto dionisíaco presto a desbordarse; pero ahora su soberbia no se dirige al sol flamígero, sino a las aguas soberanas:

Poco a poco su ceño se aborrascaba... Inquieto, el mar le salpicaba con su espuma liviana, y el héroe, sojuzgado por instinto secreto, miraba en cada ola un agravio indiscreto, y en cada gota un reto 
El poema termina con un momento climático, de vehemencia pasional, cuando el hombre se decide a dominar el mar:

\author{
Con ímpetu agresivo \\ medía atentamente los límites adustos, \\ cuando hirió sus potencias, brioso y hazañero, \\ el deseo inmediato de encadenarlo, fiero, \\ entre los eslabones de sus brazos robustos...
}

Los segmentos X y XI ilustran una retirada estratégica del hombre, que se interna, instintiva y pensativamente, en la selva montañosa, su parcela conocida. Es un momento de distensión; la selva rumorosa y umbría lo invitan al reposo. De nuevo viene a la mente el "Canto inaugural”, cuando Hércules, tras el desafío al dios solar, se adormeció por los efluvios de las fragantes rosas de un frondoso jardín. Nótese en la cita que reproducimos a continuación que a este rasgo de semejanza se unen los atributos físicos hercúleos del hombre primitivo, su fuerza latente, así como el dramatismo intenso de los últimos versos:

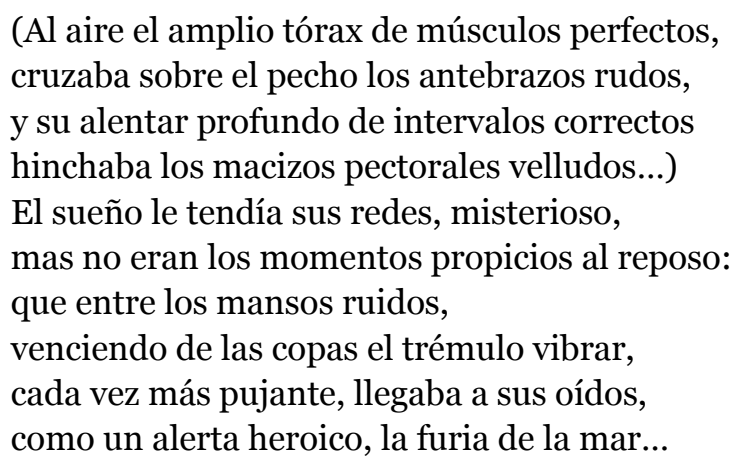

(Oda XI)

En el poema XII, el hombre convoca a una masa de gente cuya mirada enardecida recuerda el frenesí de la muchedumbre dionisíaca y el pacto que realizan, en este caso, para empezar la tala del bosque y, tras esta, la construcción de la nave, por medio de la cual el hombre dominará el mar. En el segmento XIV, la nave se va elaborando con claras notas que la encuadran dentro de la concepción apolínea del arte. En El nacimiento de la tragedia, el arte apolíneo viene representado por el arte del escultor, frente al "arte no-escultórico de la música, que es el arte de Dioniso" (Nietzsche, 2009, 41). En efecto, la nave surge en la Oda como una "arquitectura" en la que quedan reflejadas la gracia y la belleza - apolíneas- que los proto-artesanos plasman en ella, como si fuera una gran escultura. La nave es resultado de la medida, de la armonía y simetría que los hombres van imprimiendo en la madera, y no falta en el resultado final el abierto rasgo apolíneo de lo escultórico reflejado en el mascarón de proa:

Cada cual aportaba su aptitud más segura y su destreza o gracia iba dejando en ella; y así, cada mañana, la noble arquitectura brotaba con la aurora, más acabada y bella. Uno mide en la escala la altura de su paso, otro en las altas vergas las gavias acomoda, y alguien, quizás poeta o enamorado acaso, 
talla un desnudo torso de mujer en la roda...

Diose por ultimada la construcción ingrave:

una mitad es ave;

la otra mitad, sirena.

$\mathrm{Y}$ al fundar sólo un cuerpo, velamen y carena, surgió definitivo el ensueño: LA NAVE...

Tras el segmento XV, bello poema de exaltación de la nave, comienza un grupo poemático de orden panegírico dedicado a los hombres de mar. El poeta empieza cantando a los carpinteros de ribera (XVI). Podemos encontrar ecos de los ditirambos dirigidos a la actividad comercial (aquí es artesanal) de los "Poemas de la ciudad comercial", pero si en estos la característica predominante era el instinto dionisíaco, ahora, con los carpinteros de ribera, se impone el instinto apolíneo que lleva a la materia el orden y medida del artificio. Morales resuelve airosamente un tema tan prosaico como la alabanza de la artesanía constructora y, en los poemas subsiguientes, la actividad náutica de los primeros marinos (XVII), los tripulantes (el grumete, el contramaestre, los centinelas, los estibadores...), piratas, exploradores, y submarinistas. Morales alcanza tonos de enardecida alabanza a marineros desconocidos, de todas las banderas y países, de todos los mares. La universalidad de la voz poética se encumbra por encima de fronteras, culturas, y épocas históricas. Hay una lucidez visionaria preñada de optimismo. Suena el acento más puro de la poesía moraliana, conmovedoramente dirigida a héroes rudos y anónimos.

$\mathrm{Al}$ final de la Oda, antes del epifonema que funciona como despedida y cierre, se produce la apelación a la muerte. De esta forma, la Oda traza todo el arco de la existencia humana librada en las duras faenas del mar y, simbólicamente, el poeta devuelve al Mar los marinos, porque este Mar es lo Uno primordial nietzscheano de donde sale la vida ("en la mar nacisteis") y adonde se regresa con la muerte ("y en la mar moriréis"), en un ciclo interminable. Solo que en Morales esta referencia a la muerte se realiza dentro del optimismo existencial que llena, no solo la Oda, sino toda su poesía. Morales, fiel a su concepción artística paganizante, no ofrece a los marinos la gloria de una vida ultraterrena. La única gloria es la de haber librado la batalla diaria de la navegación, para terminar reposando en las profundidades submarinas:

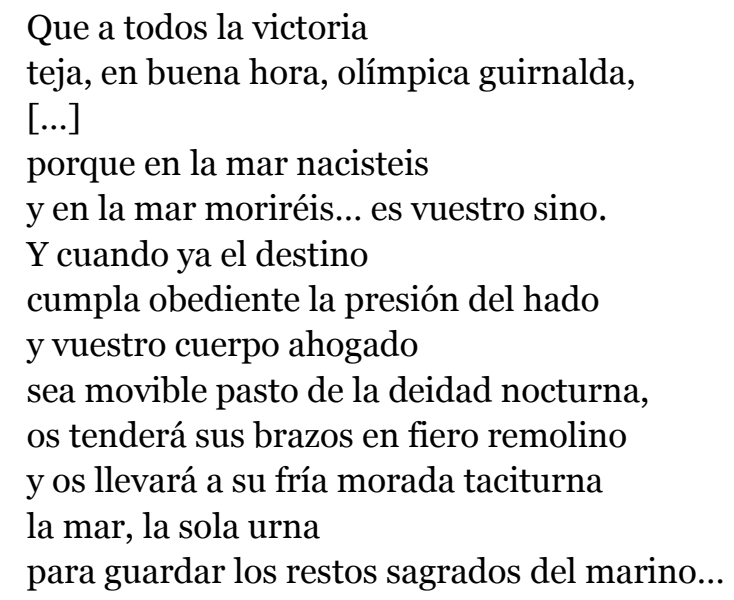

(Oda XXII)

Como puede verse, el Atlántico, con cuya invocación cierra el poeta el epifonema o epílogo de la Oda, ha llegado a una dimensión simbólica máxima, que no está reñida con el mar 
concreto que, con ojos alucinados, contempló Morales desde su atalaya atlántica en Gran Canaria. En el diafragma significativo de la poesía de Morales se verifican sin tensiones estos intercambios comunicantes.

\section{CONCLUSIONES}

Seguida o no conscientemente por Morales, la dualidad dionisíaco-apolínea, en relación con lo hercúleo, produce posibilidades de interpretación realmente potenciadoras, tanto en el nivel de los mitos como en el de los símbolos, los motivos y los significados. Esta dualidad interpretativa ilumina la exaltación que hace el poeta de la potencia humana en su brega con la naturaleza y, en general, con las fuerzas inconscientes, lo que tiene como resultado la exaltación del ingenio y la capacidad del hombre manifestados en la profesión náutica, el desarrollo comercial y el progreso urbano. Las concomitancias entre los rasgos nietzscheanos, plasmados en las dualidades correspondientes de arte escultórico y arte musical, sueño y embriaguez, belleza y orden, mesura y desenfreno, por una parte, y las configuraciones poéticas moralianas, por otra, son más que simple coincidencia, y propugnan un paralelismo conceptual e imaginístico que resulta, según creemos haber demostrado, de gran utilidad analítica.

De este modo, se entiende con más acierto el proyecto de Morales, que no consistió simplemente en una forma de organización editorial de su obra, sino en la dación de un sentido a un trabajo poético de gran coherencia. La producción de Morales tiene sus altibajos en la calidad final, pero no cabe duda de que obedece a una pasión creadora sin concesiones a la falta de compromiso, y que alcanza cotas de indudable belleza. Morales dio realce a motivos que los poetas de todas las latitudes han tratado, como el mar, la ciudad, la insularidad y la creación poética, los cuales han encontrado en los versos moralianos un canal muy personal de expresión, dentro de la adscripción del poeta a un movimiento en el que se desenvolvió con libertad creadora. Los mitos han desempeñado, en este sentido, en Morales una funcionalidad innegable, y creemos que la dualidad apolíneo-dionisíaca ayuda a integrar la variedad de usos que el poeta dio a los elementos de una tradición mitológica que quiso adaptar a su proyecto propio. Para concluir, hay que destacar, como hemos apuntado reiteradamente en el presente estudio, dos notas descollantes en la poesía de Morales: su optimismo vital y su humanismo abarcador, junto con un sentido de pertenencia a una ubicación geográfica en la que el poeta no se quedó encogido, sino que proyectó con notas de universalidad. Se trata de señas de identidad poéticas vividas con plena convicción, y que dan a la poesía del creador isleño una personalidad inconfundible.

\section{REFERENCIAS BIBLIOGRÁFICAS}

AULLÓN DE HARO, P. 1989. La poesía en el siglo XX (hasta 1939). Madrid: Taurus.

CORTÉS-ROCCA, P. 2009. "La ciudad bajo los ojos del Modernismo", A Contracorriente, 7(1), pp. 146-167.

DE LA NUEZ, S. 1973. Introducción al estudio de la “Oda al Atlántico", de Tomás Morales. Madrid: Cabildo Insular de Gran Canaria.

ESCOBAR BORREGO, F. J. 2004. "Ecos míticos y tradición clásica en Las Rosas de Hércules, de Tomás Morales”, Revista de Literatura, LXVI(131), pp. 149-170. 
ESCOBAR BORREGO, F. J. 2005. “'Deidamia es dulce nombre de la hermosura': la materia míticosimbólica como 'religión del arte' en la poesía modernista”, Moralia. Revista de Estudios Modernistas, 5, pp. 56-69.

GOMES, M. 2002. Estética del modernismo hispanoamericano. Caracas: Biblioteca Ayacucho.

GONZÁLEZ MORALES, M. B. 2015. Las estructuras antropológicas de lo imaginario en Las Rosas de Hércules, de Tomás Morales. Tesis doctoral. Las Palmas de Gran Canaria: Universidad de Las Palmas de Gran Canaria.

GUERRA SÁNCHEZ, O. 1999. "El espacio urbano como mito fundacional del modernismo canario”, en Padorno, E. y Santana Henríquez, G. (eds.), Varia lección sobre el 98. El modernismo en Canarias. Las Palmas de Gran Canaria: Universidad de Las Palmas de Gran Canaria, Servicio de Publicaciones, pp. 57-89.

GUERRA SÁNCHEZ, O. 2011. "Introducción”, en Morales, T., Las Rosas de Hércules. Madrid: Cátedra, pp. 13-37.

HENRÍQUEZ UREÑA, M. 1962. Breve historia del Modernismo. México: Fondo de Cultura Económica. HERRERÍA, A. 2014. "Martí y Darío ante Nueva York", Journal of Hispanic Modernism, 5, pp. 180-189.

MARTÍNEZ HERNÁNDEZ, M. 2010. "Islas míticas en relación con Canarias", Cuadernos de Filología Clásica, 20, pp. 139-158.

MORALES, T. 2011. Las Rosas de Hércules. Madrid: Cátedra.

NIETZSCHE, F. 2009. El nacimiento de la tragedia. Madrid: Alianza.

PÁEZ MARTÍN, J. 1999. "Tomás Morales y la atmósfera lírica finisecular en Gran Canaria”, en Padorno, E. y Santana Henríquez, G. (eds.), Varia lección sobre el 98. El modernismo en Canarias. Las Palmas de Gran Canaria: Universidad de Las Palmas de Gran Canaria, Servicio de Publicaciones, pp. 173-199.

PHILLIPS, A. W. 1959. "Rubén Darío y sus juicios sobre el modernismo”, Revista Iberoamericana 24(47), pp. 41-64.

SANTANA HENRÍQUEZ, G. 2003. Mitología clásica y literatura española. Siete estudios. Las Palmas de Gran Canaria: Universidad de Las Palmas de Gran Canaria, Servicio de Publicaciones.

SANTANA HENRÍQUEZ, G. 2004. "El canto inaugural de Las Rosas de Hércules: mito y poesía en Tomás Morales”, en García Pinilla, I. J. y Talavera Cuesta, S. (coords.), Charisterion. Francisco García Martín oblatum. Cuenca: Ediciones de la Universidad de Castilla-La Mancha, pp. 385-392.

SILES, J. 1985. “La poesía de Tomás Morales”, Caligrama 2(1), pp. 105-122.

\section{NOTA SOBRE EL AUTOR}

Santiago Acosta Aide es doctor en Filología Germánica y profesor principal en la Universidad Técnica Particular de Loja, Ecuador. 